\title{
New findings from intervention research: Youth reproductive health and HIV prevention
}

Family Health International

Follow this and additional works at: https://knowledgecommons.popcouncil.org/departments_sbsr-rh

Part of the Family, Life Course, and Society Commons, International Public Health Commons, and the Maternal and Child Health Commons

How does access to this work benefit you? Let us know!

\section{Recommended Citation}

"New findings from intervention research: Youth reproductive health and HIV prevention." Arlington, VA: Family Health International, 2004. 
New Findings from Intervention Research: Youth Reproductive Health and HIV Prevention

Meeting Report

September 9, 2003

Washington, DC

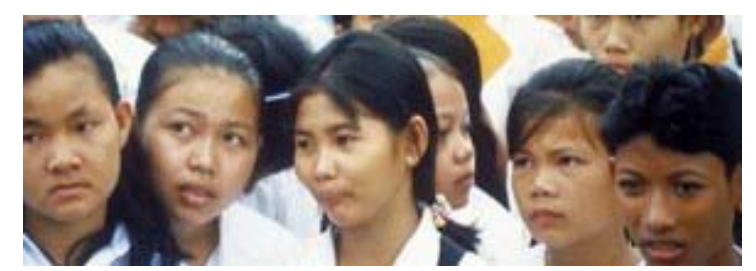

Cosponsors:

FRONTIERS/Population Council

Horizons/Population Council

YouthNet/Family Health International

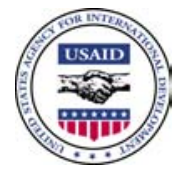

(P Population Council
YouthNet

FRONTIERS

IN REPRODUCTIVE HEALTH fhi

Hgrizons 


\section{Acknowledgements}

Staff at the U.S. Agency for International Development (USAID), Population Council (FRONTIERS and Horizons Programs), and Family Health International/YouthNet kindly reviewed this report. The speakers at the meeting reviewed the summaries of their presentations.

The Population Council is an international, nonprofit organization that conducts research on biomedical, social science, and public health fronts focusing on reproductive health and population growth. The Frontiers in Reproductive Health Program (FRONTIERS) applies systematic research techniques to improve delivery of family planning and reproductive health services and influence related policies. The Horizons Program, in collaboration with local and international partners, designs, implements, and evaluates innovative service delivery strategies to prevent the spread of HIV/AIDS and mitigate its impact on individuals and communities. Both programs are funded by USAID.

YouthNet is a five-year program funded by USAID to improve reproductive health and prevent HIV among young people. The YouthNet team is led by Family Health International (FHI) and includes CARE USA, Deloitte Touche Tohmatsu Emerging Markets, Ltd., and RTI International. This publication is funded through the USAID Cooperative Agreement with FHI for YouthNet, No. GPH-A-00-01-00013-00.

The information contained in the publication does not necessarily reflect FHI, the Population Council, or USAID policies.

Coordinators: Laura Raney, FRONTIERS; William Finger, YouthNet Reporters: Nikki Douglas, Stephanie Joyce, FRONTIERS; William Finger, YouthNet Editor: William Finger, YouthNet

Copyeditor: Claudia Ruland, YouthNet

Production: Donna Pherribo, FHI

Family Health International, YouthNet Program 2101 Wilson Blvd, Suite 700

Arlington, VA 22201 USA

703-516-9779 (telephone)

703-516-9781 (fax)

www.fhi.org/youthnet (Web site)

April 2004 


\section{Table of Contents}

$\begin{array}{ll}\text { Introduction } & 5\end{array}$

Session I. Introduction and FRONTIERS Studies 7

Setting the Stage: Learning from RH/HIV Youth Programs 7

Results from FRONTIERS Global Agenda Youth Studies

- Introduction 9

- Senegal 10

- Kenya 12

- Mexico 14

- Bangladesh 15

- Costs of Scaling Up 17

Session II. Discussion of FRONTIERS Studies 19

Session III. Results from AMREF and JHU/CCP 21

Results from a Community Randomized Trial in Rural Tanzania: the MEMA kwa Vijana Project 21

Evaluation of a Positive Deviance Youth Media Intervention in Côte d'Ivoire

Session IV. Results from Horizons Studies 24

$\begin{array}{ll}\text { Introduction } & 24\end{array}$

Teaching Abstinence in Schools: Findings from Horizons Studies 24

$\begin{array}{ll}\text { Transitions to Adulthood in South Africa } & 27\end{array}$

Session V. Closing Session 28

Discussion of AMREF, JHU/CCP, and Horizons Studies 28

Panel: Reflections on Key Lessons of the Day 29

Appendix 1: Meeting Agenda $\quad 32$

Appendix 2: Summary: Discussion of Lessons Learned from

Operations Research 


\section{Introduction}

On September 9, 2003, FRONTIERS/Population Council, Horizons/Population Council, and YouthNet/Family Health International co-sponsored a technical meeting in Washington, D.C., "New Findings from Intervention Research: Youth Reproductive Health and HIV Prevention." Approximately 150 HIV/AIDS, reproductive health, and youth development experts from a diversity of organizations and backgrounds participated. The purpose of the meeting was to disseminate newly available research findings on how to change youth reproductive health/HIV knowledge, attitudes, and behaviors in developing countries. The meeting also sought to stimulate discussion on lessons learned, best practices, and recommendations for future youth programs and research.

Shanti Conly of the U.S. Agency for International Development welcomed the group, pointing out the milestone this field has reached with this new round of research results. Rigorous evaluation of different program approaches is important so that policy-makers know how best to invest limited funds. Yet there have only been a limited number of evaluations of youth $\mathrm{RH} / \mathrm{HIV}$ programs with strong research designs in developing countries - only 39 studies as of 2001.

The ten additional studies presented at this meeting thus represent a significant expansion of the knowledge base. Several of these studies including the AMREF project from Tanzania also assess a new approach of linking parallel interventions in schools, clinics, and the community. The AMREF project has the most ambitious evaluation in the group: a randomized control trial that supplements self-reported behaviors with biological markers. Even so, the interventions themselves are low-cost and the quality of implementation was robust. This latter point is important - in looking at evaluations that show only modest impacts on behavior, it is often unclear whether it was the intervention design or its implementation that was flawed.

Conly emphasized the importance of having realistic expectations of research studies, noting that "knowledge is incremental and epiphanies few." She hoped that this new round of studies would provide fresh insights in addition to reinforcing previous research results. Moreover, part of the value of this meeting was the opportunity for experts to provide synthesis and interpretation of new findings across studies, thereby providing guidance for future program directions and priority topics for further research.

Dr. Nancy Williamson, director of the YouthNet program, explained the types of studies that were going to be discussed during the day. She emphasized that these were new findings from operations research studies designed to promote reproductive health and HIV prevention among youth in developing countries. All of the studies were large scale, fairly expensive, well evaluated, and either experimental or quasi-experimental in design. Most had multiple components, meaning they involved interventions in the media, school, health services, and/or the community (such as peer education). Some of the studies were planned as long ago as five years ago and hence may not have been as explicit about the current emphasis on "ABC" approaches (abstinence, be faithful, and 
condoms). Also, many of the studies went to the field about the time that HIV interventions began proliferating in some of the countries, which may complicate the attribution of effects of the intervention in some cases.

This report summarizes the presentations and discussions at the meeting, following the meeting agenda. All of the plenary presenters used PowerPoint slides. These are available on-line through YouthNet, along with this report, at http://www.fhi.org/en/Youth/YouthNet/Publications/otherpubs.htm (scroll to Meeting Reports). Please refer to these slides for more details. 


\section{Session I. Introduction and FRONTIERS Studies}

\section{Setting the Stage: Learning from RH/HIV Youth Programs}

Dr. Douglas Kirby, ETR Associates

Dr. Kirby provided an overview of reproductive health/HIV youth programs, drawing on material published in Emerging Answers (National Campaign to Prevent Teen Pregnancy, 2001), Addressing Young Adult Reproductive Health: Actions for the Next Decade (Pathfinder, 2001), and Sexual Behavior, HIV and Fertility Trends: A Comparative Analysis of Six Countries (USAID, 2003). He pointed out that multiple kinds of programs exist, including sex and HIV education programs, clinics, mass media, youth development, and others. These programs have multiple goals including decreasing unintended pregnancy, decreasing sexually transmitted infections (STIs), including HIV, and improving sexual health in other ways.

Many RH/HIV studies have demonstrated an increase in knowledge, clarification of sexual values, and improvement in attitudes and values. However, it is also important to actually change behaviors, e.g., delay of initiation of sex and for those who are sexually active, reduced frequency of sex, increased correct and consistent contraceptive use (including condoms), and reduced number of sexual partners. He then addressed three questions regarding changing these behaviors:

1. Can individual programs have a significant impact on these behaviors? From a review of data from sex and HIV education studies that employed an experimental or quasi-experimental design, had a sample size larger than 100, and measured impact on behavior, he concluded that some but not all of the programs that met these criteria had positive effects on one or more sexual behaviors. About one-third of programs significantly delayed initiation of sex, reduced the frequency of sex, and increased contraceptive use; about one-half increased condom use. These programs did not have negative effects, such as increasing sexual activity. He found that emphasis on both abstinence and using condoms or contraception is compatible, not conflicting.

The effectiveness of programs is determined in part by the characteristics of the programs, the characteristics of the samples targeted, and the characteristics of the surrounding communities. Kirby summarized the 10 characteristics of effective education programs, which include:

- focusing on sexual risk-taking behaviors

- having a theoretical basis that identifies important risk and protective factors to be changed

- giving a clear message about avoiding unprotected sex

- involving participants in interactive activities that personalize messages

- lasting long enough to complete important activities

- training teachers who believe in the program

Programs have been effective with many types of youth and may be especially effective with higher risk youth. 
There are fewer studies measuring the impact of clinic, mass media, and youth development programs. Some research has found that clinic and youth development programs have reduced sexual risk-taking behavior. While mass media projects did not consistently change behavior, some increased the use of clinics, and a few increased condom or contraceptive use, although these effects did not last over the long term.

\section{Is it possible to have a countrywide impact on sexual and contraceptive behaviors?}

He examined data from the United States and Uganda and concluded that it is possible to have a countrywide level of impact. In the United States, the percentage of 9th to 12th graders who had ever had sexual intercourse or who had had four or more partners declined during the 1990s, while condom use rose. In Uganda, among those ages 15 to 24 , the median age of first sex increased and number of partners declined, while condom use increased among those who had sex with a non-marital or non-cohabitating partner.

Uganda: Percent of Single 15-24 Year Old Men and Women Who Had Sex in the Past Year with a Non-Marital/Non-

Cohabitating Partner Who Used a Condom at Last Sex

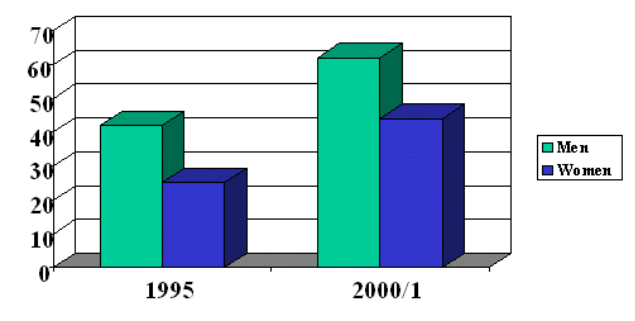

Uganda: Percent of Single 15-24 Year Old Men Had Sex in the Past 6 or 12 Months with Three or More Partners

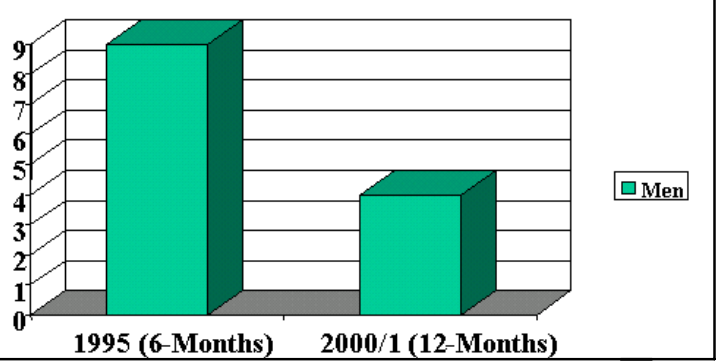

3. Did these changes in behavior significantly affect important reproductive health outcomes? Yes, the U.S. pregnancy rate declined and the Ugandan HIV prevalence rate declined, especially among young people. Dr. Kirby concluded that some but not all programs are effective at changing behavior, including both sexual activity (abstinence, frequency, and number of partners) and condom or other contraceptive use. These behaviors can be changed nationwide and help achieve important national goals. Among youth, programs should simultaneously encourage abstinence, partner reduction, and use of condoms or other contraception. 


\section{Results from FRONTIERS Global Agenda Youth Studies}

\section{Introduction}

Dr. Susan Adamchak, FRONTIERS

In 1998, FRONTIERS began a series of youth studies in four countries: Bangladesh, Kenya, Mexico, and Senegal. The studies tested the feasibility, effectiveness, and costs of multicomponent interventions designed to improve knowledge, attitudes, and behavior of adolescents ages 10 to 19 .

Dr. Adamchak explained that while donors supported youth programs, they did not understand which types of efforts were most effective. There were only a few large-scale studies underway, and the relative value of these multicomponent programs was not clear. Also, little information on the cost of youth programs existed. More information was needed on how to link diverse programs and multiple interventions. Donors and program planners needed more evidence on what types of programs to design.

In these conservative, religious countries with strong family traditions, questions existed initially about whether communities would support adolescent health interventions. Hence, project staff spent a great deal of effort to garner community support for new programming centered on adolescent reproductive health. All the studies worked with youth ages 10 to 19 (except in Bangladesh where the ages were 13 to 19) and parents.

The studies tested the feasibility, cost, and effectiveness of two interventions: one involving community and health services and the second adding a school intervention. Thus, several sites in each country received community- and clinic-based services, while other sites received these services plus school-based services. Control sites received the prevailing government and nongovernmental services. The studies looked at a broad range of reproductive health knowledge, attitudes, and beliefs that varied by country. All took place in the context of evolving social norms and contexts.

The community intervention included intensive sensitization in which religious and community leaders and peer educators organized briefings and outreach events. In the health services intervention, peer educators and providers at public and private facilities were trained to offer youth-friendly services. In the school-based intervention, teachers, peer educators, and guidance counselors were trained to teach a life skills curriculum that included modules on reproductive health, sexuality, and HIV/AIDS.

Preliminary findings showed that there were no large or significant differences between the intervention and control areas with regard to changes in behavior but that knowledge and attitudes did change in many settings. No clear pattern emerged among the four countries to indicate that the three-component intervention sites (those including the school intervention) outperformed those with only community and health services interventions. 
The intervention sites generally did better than the control sites, although results are mixed depending on the indicator. For example, changes in knowledge of HIV/AIDS increased at endpoint in all intervention sites in Bangladesh and Mexico, but knowledge declined in an intervention site and the control site in Kenya.

Factors likely affecting the results included varying intensity of the interventions, migration of older youth away from the study sites, contamination of the control sites by the presence of other reproductive health and HIV/AIDS projects, and overall social change. One of the key findings was that "one size does not fit all" - the package of interventions did not address all groups equally. The studies also showed that a small proportion of those ages 10 to 19 were sexually active.

Though the studies achieved only modest changes, Dr. Adamchak pointed out the successes the studies achieved. The interventions only ran for 15 months yet showed reduced sexual activity among males, although the change did not reach statistical significance in all countries. The studies also demonstrated that these interventions could be undertaken in these conservative communities, where more than 80 percent of parents approved of giving reproductive health information to adolescents. The studies also contributed to the growing understanding about the costs of such interventions and how to measure them.

Dr. Adamchak then introduced a series of presentations on each of the four countries and on cost issues.

\section{Serving the Reproductive Health Needs of Adolescents in Senegal}

Dr. Nafissatou Diop, FRONTIERS/Senegal

Dr. Diop reported preliminary findings from the FRONTIERS youth study in Senegal. In 1999, FRONTIERS began a three-year collaboration with the World Health Organization (WHO), Ministry of Health, Ministry of Education, Ministry of Youth, the Center for Research and Training in Population (CEFOREP), and the Population Training Group (GEEP) to test the feasibility, effectiveness and cost of several interventions to improve the reproductive health of youth aged 10-19. Senegal had several policies in place that favored adolescent reproductive health. In a fortunate coincidence, the Office of Adolescent Health was created in 1999 within the Ministry of Health during the course of 
the study. In addition, an important law allowing youth under 18 to obtain reproductive health services without parental consent was being considered by Parliament.

The study took place in three communities in northern Senegal. Saint Louis and Louga served as intervention sites where community- and clinic-based interventions were offered; Saint Louis also introduced a school-based intervention. Diourbel served as a control site. The community intervention included sensitization on adolescent reproductive health for community and religious leaders, communication with parents through women's groups, and education sessions led by peer educators. The community intervention targeted out-of-school youth and identified and utilized existing youth networks. A total of 70 peer educators were trained using a curriculum developed with the assistance of FHI. The intervention tried to maintain the same group of peer educators. In the clinic-based intervention, providers and peer educators were trained to offer youth-friendly services. Providers implemented youth-friendly services over 15 months in seven clinics. The school intervention included reproductive health information in the school curriculum, and peer educators organized other activities.

Study results showed that community members strongly endorsed improving youth reproductive health but expressed mixed feelings about adolescent sexuality. Religious leaders believed that parents should discuss reproductive health issues openly with their children. Though both parents and young people approved of informing youth about reproductive health, most favored promoting abstinence rather than contraception.

Young people's knowledge of reproductive health increased. The proportion of adolescents knowing one or more contraceptive methods rose significantly (from 49 percent to 61 percent in St. Louis and from 59 percent to 69 percent in Louga). Knowledge of the consistent and correct use of condoms also increased significantly and ended up being nearly universal in both intervention sites. The proportion of youth knowing the period when a girl can become pregnant increased modestly from 21 percent to 26 percent in St. Louis and from 14 percent to 25 percent in Louga. When youth were asked about ways to avoid STIs, references to abstinence increased.

Overall, sexual activity among unmarried Senegalese youth ages 10 to 19 is low: 20 percent of boys and 4 percent of girls reported that they had ever had intercourse. Among sexually experienced youth, the proportion reporting a sexual encounter during the last six months decreased from 48 percent to 36 percent. The average number of sexual partners dropped from 2.1 to 1.5 , implying that more youth are choosing fidelity to one partner.

However, condom use also declined. The use of condoms at first sexual experience decreased from 32 to 21 percent in St. Louis, and use at last intercourse dropped from 48 to 34 percent. Significant decreases also took place in Louga and the control site. The intervention introduced messages on abstinence, fidelity, and condoms, but providers highlighted abstinence and fidelity, which may have contributed to a decline in condom use. 
The intervention faced many challenges at the local, district, and national levels. Some political changes took place that may have affected the intervention. Health providers complained about workload. There were problems with the supervision of peer educators, so providers were asked to supervise them. Peer educators had difficulty initiating programs due to lack of confidence and skills. In addition, contraception is still taboo or controversial, particularly use by adolescents, and condom promotion is difficult in Senegal.

The costs for implementing all three interventions over two years totaled approximately US $\$ 100,000$, with costs for the community and clinic interventions totaling $\$ 74,000$. The community intervention was the most costly (about $\$ 40,000$ ), followed by the clinic (about \$34,000), and school interventions (about \$26,000). Most expenditures were for planning and training at the start of the project.

At the conclusion of the project, communication, parental attitudes, knowledge and attitudes about contraception (including condoms), and sexual activity showed significant changes in both intervention sites, compared to the control site. The use of services by adolescents was not significantly different in the intervention sites, however.

The intervention findings sparked interest among other agencies to launch youth programs. UNFPA is reviewing its adolescent reproductive health strategy in light of these research results. The Ministry of Health and WHO plan to scale up elements of the clinic and the community components in other districts. The intervention was timely in that it coincided with the creation of the Ministry of Health's Office of Adolescent Health, and helped the new agency to develop its strategy.

\section{Innovative Project Delivers Reproductive Health Information and Services to Young People in Western Kenya}

Carolyne Njue, FRONTIERS/Kenya

Young people in Kenya have limited knowledge of reproductive health and face many challenges in their transition to adulthood, including risk of HIV infection. In 1999, the prevalence of HIV was 14 percent among adults ages 15 to 49 , but prevalence has since declined to 10 percent. Until 1999 there was no national policy on adolescents, but guidelines are now being put in place by government and nongovernmental agencies.

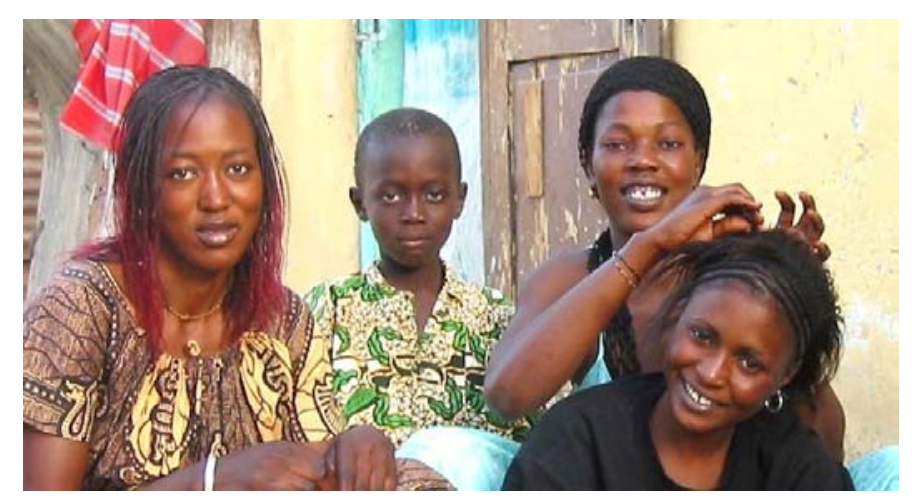

In 1999 FRONTIERS initiated a three-year project in Kenya to test the feasibility, effectiveness, and cost of interventions to improve adolescent reproductive health among youth ages 10 to 19 . The project, implemented jointly with the Kenyan government and 
the Program for Appropriate Technology in Health (PATH), took place in six rural communities in the western province of Kenya, where most families depend on farming. All projects were managed at the district level. As with the FRONTIERS studies in Bangladesh, Mexico, and Senegal, interventions occurred in three sectors: community, health services, and schools. The community intervention later included 80 religious leaders, a process that had an important impact on the project's acceptance. Young people participated in clubs and other activities that were part of the school and community interventions

The clinic intervention did not result in a significant increase in visits to clinics. Most adolescents came to clinics for antenatal care. Results showed increased knowledge of family planning, statistically significant in the two-intervention site but not statistically significant in the three-intervention site.

Endline results showed that 90 percent of adolescents and 95 percent of parents disapproved of premarital sex. Knowledge of the fertile period and family planning improved among all girls and older boys in Site A (two interventions). In Site B (three interventions), knowledge of family planning among boys did not change and declined among older girls. The results show that even among the older age groups, almost half of the boys and over two-thirds of the girls reported no sexual experience. However, the proportion of adolescents who had ever had sex increased among older boys and girls in Site A, and in the control group, increased among older girls. In Site B (three interventions), sexual activity decreased by about 10 percent among girls, a statistically significant proportion.

Use of protection at first and last sex for girls ranged from 20 percent to 35 percent and for boys, ranged from 12 percent to 41 percent. Among the girls, no significant changes were found for contraceptive use at first sex, but at last sex there were significant increases in use in all sites. For the boys, however, the findings are not so encouraging. The only improvement was among boys in site A using protection at first sex, whereas in site $\mathrm{B}$ there was a significant decline in use of protection at last sex.

While the project was underway, the Kenyan government mandated that schools provide students with information on HIV/AIDS. Teachers in the school intervention areas reported that their training in the life skills curriculum enhanced their ability to carry out this mandate.

Costs for all phases of the project (planning, implementation, monitoring, and service delivery) totaled US $\$ 153,000$. Non-financial costs (such as the reallocation of existing services or staff time) totaled US $\$ 16,000$. Financial costs would be significantly lower in the event of scale-up, as many of the planning costs (US\$28,000) would be eliminated, and salaries for local staff would be lower.

The Population Council and PATH are working with the Kenyan government to institutionalize successful aspects of the intervention, replicate the project in other areas of the western province, and document improvements made during the process of scaling up. 


\section{Adolescent Reproductive Health and Sex Education Interventions in Mexico

\author{
Dr. Ricardo Vernon, FRONTIERS/Mexico
}

Dr. Vernon gave background information on the social and institutional changes taking place in Mexico. One of the most striking demographic trends in the last 20 years has been the increase in median age at first marriage to 27 years for men and 24 years for women. The HIV prevalence rate among 15 to 44 year olds is low ( 0.3 percent). Adolescent health programs have been a priority since the mid-1990s. This has been reflected in several health policy changes such as mandatory sex education, national reproductive health guidelines, and strong media campaigns. The Ministry of Health and Social Security as well as several nongovernmental organizations (NGOs) sponsor large adolescent health programs.

From 1999 to 2002, FRONTIERS worked with the NGO MEXFAM to test the feasibility, effectiveness, and cost of community-, clinic-, and school-based interventions to improve the reproductive health of youth ages 10 to 19 . The interventions were introduced through MEXFAM's Young People Program (YPP). Eight cities in central Mexico were selected as intervention sites, and four similar cities served as control sites.

The cities in the experimental group had populations of about 94,000 adolescents, 160 schools, 60 clinics and hospitals, 200 private clinics, and over 100 pharmacies. The intervention involved providing training on adolescent reproductive health to providers and pharmacists in health facilities and peer educators in the community. MEXFAM developed a set of training courses, which consisted of a $40-$ hour course for peer educators and volunteers and a 35 -hour adolescent medicine course for health providers. Four of the intervention cities also received a school-based intervention in which trained teachers conducted events to strengthen existing sex education programs. Goals were set for each type of intervention.

Strong increases in the awareness of AIDS were observed, especially among youth aged 10-14. There was a slight increase in knowledge of the fertile period among adolescents. Approval of premarital sex decreased during the project, especially in the intervention group. However, the already high approval of contraceptive use increased, as did the use of condoms among sexually active youth. Post-intervention surveys showed an increase in the proportion of male and female adolescents who spoke with their parents about reproductive health issues. These findings may have been influenced by the introduction of a national adolescent health curriculum, which coincided with the intervention. 
Costs in both intervention sites were similar, about US\$235,000. The school-based intervention was costly, due to the high non-financial costs of about $\$ 100,000$ (such as staff time and reallocation of staff tasks). The community activities had the highest financial costs (about $\$ 40,000$ to $\$ 60,000$ ), reflecting the varied scale and frequency of activities.

MEXFAM has adopted several project management strategies introduced during the project. These include: a new information system focusing on data collection for on-site decisionmaking; new criteria and follow-up procedures for volunteers; and a focus on innovation in programming for youth.

\section{Adolescent Reproductive Health Findings from Intervention Research in Bangladesh}

Ismat Bhuiya, FRONTIERS/Bangladesh

Dr. Bhuiya introduced the context for the Bangladesh study. In Bangladesh, 78 percent of girls are married before age 18, which is the legal age of marriage. Among married females aged 15 to 24, 43 percent use family planning and 4 percent use condoms. Currently HIV/AIDS prevalence is less than 1 percent. Intravenous drug use is causing the HIV rates to rise.

Adolescents, who make up about 25 percent of the population of Bangladesh, have limited access to reproductive health information and services. Young people are vulnerable to a variety of reproductive health risks, including unwanted pregnancy and STIs. Nevertheless, reproductive health education has not been a part of the education curriculum, and the existing health service delivery system is not addressing the needs of unmarried adolescents. Only in 2003 did Bangladesh establish a national youth policy.

In 1999 FRONTIERS worked with the Ministry of Health, the Urban Family Health Partnership (UFHP), and two NGO partners to test the feasibility, impact, and cost of several interventions to improve the reproductive health of adolescents aged 13 to 19 . The 18-month intervention took place in two experimental urban sites, while a third similar control site received prevailing services.

Both sites received the community intervention, which involved sensitization and outreach to community stakeholders (parents and religious and community leaders) to encourage local support. Out-of-school adolescents were offered a 20-session "life skills" curriculum that included reproductive health; peer educators organized community events that included reproductive health content. The experimental sites also received a clinical component, in which providers were trained to offer a variety of affordable, adolescentfriendly services. One site also received a school-based intervention, in which trained teachers provided a life skills curriculum to eighth- and ninth-level students (ages 14 to 15$)$.

Study findings from a parents survey showed that almost all fathers ( 90 percent) approved of school-based sex education and clinical services. About 77 percent of 
mothers expressed approval of such education, though less than half (42 percent) of mothers and only 10 percent of fathers provided reproductive health information at home. A survey of adolescents showed that 59 percent of females, regardless of site or exposure status, reported that parents were their main source of reproductive health information, compared to 3 percent of males. Younger adolescents were more likely to report a teacher as the main source for reproductive health information. Females were more likely to have received reproductive health information than males. Younger females were more exposed to this information than older ones in the school intervention site, reflecting the grade levels targeted by the intervention.

Sexual activity outside of marriage is infrequent. Of 1,726 unmarried adolescents surveyed at endline at intervention sites, only 6 percent (130 boys and eight girls) reported being sexually experienced.

The school-based intervention increased overall knowledge of several aspects of reproductive health, though knowledge levels varied. Nearly all adolescents, for example, had heard of HIV/AIDS; knowledge of how HIV is transmitted increased in all sites but in larger amounts at the intervention sites. The knowledge of a woman's fertile period increased from 5 percent to 14 percent in the school intervention site.

Nearly 5,000 adolescents received at least one service from youth-friendly clinics. The majority ( 87 percent) obtained reproductive health services - mainly tetanus toxoid vaccines for girls who were pregnant or contemplating marriage, a strong but unanticipated impact. Clinic attendance was strongest in the site where all three interventions took place

The Bangladesh study encountered many obstacles. Working males were not able to attend sessions. There was a high turnover rate among the male facilitators who were in transition from school and left to take jobs or enter universities. On the other hand, positive changes resulted: other schools were willing to introduce reproductive health education; social inhibition about discussing reproductive health decreased; and the communication gap between teachers and students diminished.

The combined cost of all three interventions was US $\$ 41,388$. The cost of the clinic-based services was relatively low $(\$ 2,352)$ because it built upon the existing service delivery structure and training materials. The average financial and non-financial costs of the community- and school-based interventions were similar, about $\$ 12,000$ each.

The Ministry of Health and Family Welfare used the study findings in support of a proposal for school-based HIV/AIDS education to the Global Fund to Fight AIDS, Tuberculosis, and Malaria. In addition, Save the Children (UK) included the teaching model and outreach material in their program, and several national organizations will use project materials to assist vulnerable women. Finally, in 2002, the school and clinic interventions were expanded to 34 additional schools and 88 health facilities. 


\section{The Costs of Scaling Up}

Dr. Barbara Janowitz, Family Health International

Dr. Janowitz discussed the cost of scaling up the interventions in Bangladesh, Kenya, Mexico, and Senegal. First, she presented basic issues on cost and factors affecting the costs of scaling up. Scale-up costs are not a simple multiplier of the costs incurred in an operations research project.

People often think about cost in terms of how much money they pay for something. However, economists take a broader perspective on costs, considering monetary versus non-monetary costs, since costs sometimes involve no monetary payment. The challenge is to think of cost in terms of resources rather than money. Also, the process of producing the product or the quality of the product may vary.

To demonstrate this concept, Dr. Janowitz gave an example of two women baking a cake and asked which cake costs more and what would be the additional cost of baking two cakes. In the first case, one baker may have to purchase supplies while the other may already have them on hand. Since the resources that they use are the same, the cost is the same. When considering the cost of baking an additional cake, one must consider the country or area where the cake is being baked because there are price differences from one country to another. For the two bakers, the cost may be $\$ 2.40$ for flour and $\$ 2.85$ for sugar in one country, compared to $\$ 1.20$ and $\$ 1.43$, respectively, in another country. Thus costs will differ even though the resources used do not differ.

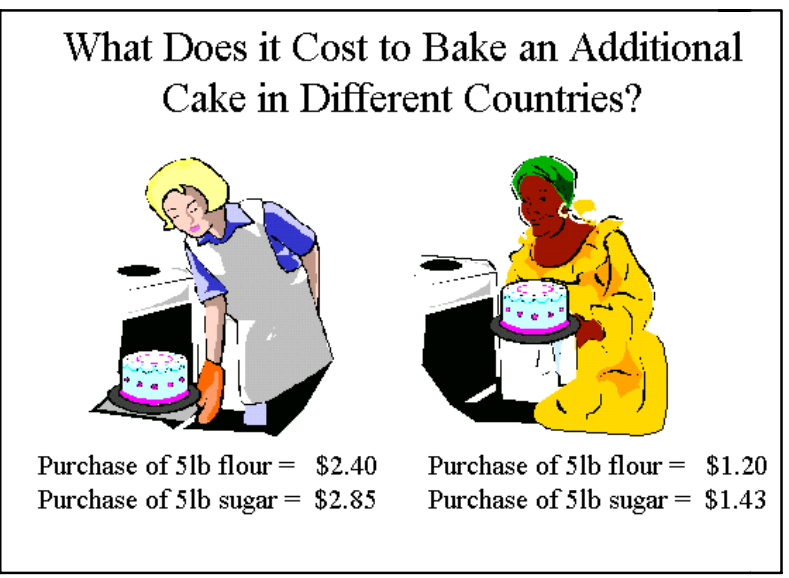

As with baking cakes, the cost of scaling up a youth project depends on:

- the amount of resources used, regardless of whether they are purchased

- the unit costs of the resources, including the opportunity costs of labor

- whether scale-up is large or small (the more cakes, the higher the total costs)

- whether scale-up affects the production process

In a simple model to estimate costs, inputs (labor, materials, capital, etc.) go through a series of processes (planning, implementation, service delivery, etc.) and produce outputs. In the youth projects, the outputs were the new or increased educational and service delivery programs. The youth projects - as well as the process of scaling them up to a larger arena - involves three stages: planning and designing the intervention; implementation, including training and service delivery; and monitoring.

In the youth projects, the labor used in each of these planning sessions was identified and measured, which allowed the cost to be determined - such as a consultant used in designing a curriculum. The implementation phase includes the costs of all training 
sessions including those to train trainers, and those to train intervention personnel (clinic staff, teachers, peer educators, and community leaders). The costs of each session include the costs of trainer and trainee labor, regardless of whether these persons receive compensation to carry out the training or to attend the training session.

The costs of the education and service delivery components depended on such factors as the number of youth visiting clinics, teachers spending more time on family life education programs, and guidance counselors spending more time talking to students about reproductive health concerns. The costs of these outputs include peoples' time and supplies (STI drugs, condoms, etc.). The youth projects tracked the number of visits and encounters and measured how much the resources used in each type of intervention cost. Time and travel costs of persons who monitor and supervise were also included.

The cost of scaling up is not a simple multiplier. Many factors, such as the types and number of activities the project chooses to undertake and the potential economies of scale, affect the cost of scaling up. In each phase (planning, implementation/service delivery, and monitoring), many factors must be considered. In some cases, operations research costs are higher than scale-up costs, such as the generally higher cost of contracted employees compared to government ministry staff. In the scale-up, costs should be lower as activities are likely to be taken over by the Ministry of Health.

In considering what components of an intervention to scale up, a policy-maker first needs to think about whether the intervention yields the desired outcomes. If it does, then, is it affordable? Specifically, can the full intervention be scaled up or will the scale-up include only some parts of the full intervention? For example, will intensive monitoring and supervision be scaled back? If the intervention is not affordable by the country, then is there another donor that is willing to fund some of the project's costs? And, if the project is changed so as to lower its costs, will we get the same outcomes as if the full project had been repeated? For example, with less intensive monitoring to ensure that the intervention is carried out as planned, will service provision and ultimately impact suffer? 


\title{
Session II. Discussion of FRONTIERS Studies
}

\author{
Discussion of Implementation, Results and Costs \\ Moderator: Susan Adamchak, FRONTIERS
}

Dr. Adamchak provided a brief summary of the presentations. She emphasized that the youth studies were complex in design, making it difficult to identify specific findings by type of intervention. Even so, two key messages were clear. First, the community interventions tended to do better than the school interventions.. Second, since these studies were not controlled clinical trials, the findings are not sharply defined. Various external factors affected the results. For example, Mexico, Senegal, and Kenya had a change in government during the study, which affected various policies such as school sexuality education requirements. In addition, other projects were underway simultaneously such as the MTV "Staying Alive" HIV prevention campaign adapted to the community level in Senegal, with support from YouthNet.

She then moderated questions and comments from audience members, although lack of time prevented a full discussion on many of the points raised. Participants often spoke of their own experiences, with some questions pointed to specific aspects of the studies and others raising broader themes. Some questions could not be answered because the study results are still being analyzed, explained Dr. Adamchak. Preliminary analysis shows that there are some commonalities as well as differences in the answers to the questions participants raised, she explained, depending on the particular country situations and communities involved. Also, a lot of unanswered questions need further research, she said in concluding the discussion.

\section{Questions and Comments}

Several questions were raised about the study design and the indicators that were used.

- In the baseline, were relationships of young girls with older males considered?

- Since teachers may not be the most positive role models, how were teachers selected?

- Why did the researchers chose knowledge of fertile period as a finding?

- How meaningful and reliable are the results on the knowledge of fertile period and sexual activity?

Other comments and questions included:

- We need to ask ourselves what are the outcomes we are measuring and how are they measured. Although we are getting better at measuring behavior, we still have some difficulties.

- Adolescents are not sure what behaviors to report so their responses may not be meaningful. For example, sexual activity is controversial. Data may be biased because we measure reported sex and not actual sex.

- Since there are constant changes going on in these environments, how are we capturing this? Are there ways to systematize these changes in the social area? 
Another theme related to concerns about scaling up.

- Participants raised questions about the degree of intensity in a scaled-up approach, about the resources needed, and the importance of having existing infrastructures.

- Without the infrastructure, you may not have the expertise that you need, so you may have to do remedial training. Most schools and clinics may have the infrastructure in place, but not communities, especially in rural areas.

Other miscellaneous comments included:

- One participant expressed frustration with the studies because large investments of resources and time were made despite the modest behavior changes (although substantial changes in knowledge and attitudes did result). She felt that these programs were not very successful and showed mixed results.

- Another participant was struggling to find the take home message in the mixed results that were presented. Also, how comfortable are we with the results given the fact that the environment changed in Senegal and Kenya and to a greater extent in Mexico?

- In Kenya, one participant noted that the results of a World Bank school-based intervention study were much different than the FRONTIERS results, raising doubts for him about which study results represent the true picture of this type of intervention.

- How are these studies contributing to what we know already?

- What do we know about making health services more youth-friendly?

- What similarities were there in the community interventions across the studies?

- How did unit cost vary across the project stages and how do you measure this unit cost? 


\section{Session III. Results from AMREF and JHU/CCP}

\section{Results from a Community Randomized Trial in Rural Tanzania: the MEMA kwa Vijana Project}

David Ross, AMREF/London School of Hygience and Tropical

Medicine/Tanzanian National Institute for Medical Research Bernadette Cleophas-Mazige, AMREF

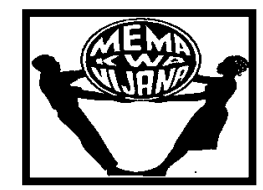

Ross first discussed the structure of the study, in the context of previous research focusing on schools in Africa. Because a large proportion of youth ages 10 to 14 attend school, this setting is a potentially cost-effective strategy for targeted HIV prevention. This project was developed to provide objective, biological endpoints on an intervention among youth and schools. This study was a community, randomized trial among 20 rural communities in the Mwanza region. Each community contains five to six villages, and an average of six primary schools and two health facilities. Half were intervention sites and half control sites. It was a three-year intervention (1999 to 2001), targeting those in their last three years of primary school.

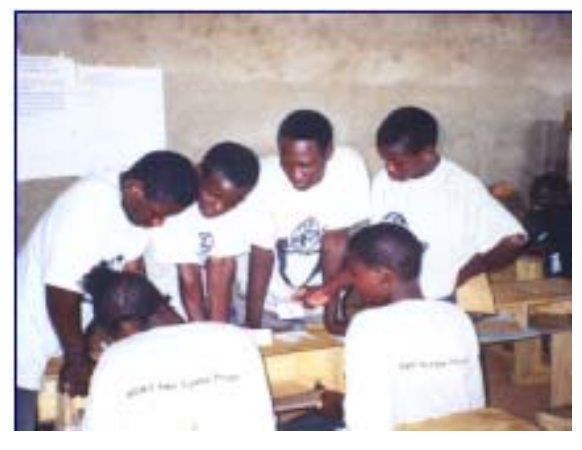
Enrolled in the project evaluation were 9,645 youth with a median age at baseline of 15 years. The project sought to delay the onset of sexual intercourse, decrease risk behaviors, and increase appropriate use of health services. Biological markers included measurements of HIV incidence, genital herpes, other STIs, and pregnancy rates.

The intervention was designed so that it could be sustainable and replicated at a national level within five years of the end of the trial. The intervention had four components: community activities, sexual and reproductive health education in grades 5 to 7 (ages 12 to 17), youth-friendly reproductive health services, and community-based condom promotion and social marketing by youth. The community component included advisory committees, religious leaders, and youth health weeks with dramas and other activities. School education involved training teachers and peers to assist in activities, development of teacher guides and training materials, and the involvement of the district education officials. Health services involved contraception, and syndromic STI treatment; providers were trained in youth-friendly issues such as privacy, youth rights, and confidentiality. Outreach activities included health days at the facilities and at schools. At the community level, trained local youth promoted social marketing of condoms.

Monitoring indicated that it was feasible to use the innovative methods of edutainment (drama, games, etc.), to address challenging sexual and reproductive health issues (condom use, transactional sex, etc.), to make health services more youth-friendly, and to implement multiple components on a large scale to high standards in a resource-poor setting. More than 150 teachers, 2,000 peer educators, 62 head teachers, 14 ward 
education coordinators, 10 district inspectors of schools, and 70 health workers were trained.

Cleophas-Mazige then described the results, comparing baseline to post-intervention surveys among the trial cohort. Regarding knowledge and reported attitudes, the changes in the intervention communities were better (statistically significant) than in control areas in knowledge and attitudes about HIV and other STI acquisition, pregnancy prevention, and attitudes toward sex, among males and females. Regarding behaviors, males in the intervention areas reported delayed sexual debut and fewer sexual partners during the project, compared to the control areas (borderline statistically significant). There were no such differences among females. Both males and females in the intervention area used condoms more frequently; however, the absolute proportions using condoms remained relatively low. Finally, there was no evidence of any consistent or statistically significant impact of the intervention on biological outcomes for HIV incidence (though the power of the study for this outcome was low), genital herpes, other STIs, or pregnancy rates.

The investigators concluded that it is feasible to implement a large-scale, multicomponent sexual health program through existing government staff and structures in Africa, with high quality and coverage, and to evaluate the study rigorously, including measuring biological outcomes. They found gender differences in changed outcomes in sexual behaviors to be very important. The evaluation suggested a greater ability in changing reported behaviors among males, compared to females. The duration of the follow-up may have been too short to see the impact of the intervention in biological outcomes. Forty percent of the impact evaluation cohort only received one year of the in-school intervention. They found some evidence that more years of exposure to the intervention yielded increasing benefits.

Finally, they concluded that additional interventions may be needed to achieve an impact on HIV, STI, and pregnancy rates in the short-term. These intervention might include intensified mass media, specific interventions targeting out-of-school youth, more intensive community activities to try to change general adult and adolescent norms, and more accessible facilities for counseling and voluntary HIV testing. 


\section{Evaluation of a Positive Deviance Youth Media Intervention in Côte d'Ivoire}

Stella Babalola, Johns Hopkins University/Center for Communication Programs.

Babalola described a multi-media intervention that emphasized what she termed, "positive deviant behaviors," including abstinence and consistent condom use. The campaign targeted primarily girls ages 13 to 20 in urban and semi-urban areas of Côte d'Ivoire, with a secondary target of boys and parents. The campaign slogan was "Love without risk is a PL.U.S."

The campaign used posters, key holders, two television jingles, leaflets, brochures, a community radio variety show series, a popular song, t-shirts, and a photo- novella to promote the campaign slogan, as well as contests, rallies, sports events, and other activities. Youth adopting so-called "positive deviant" behaviors gave testimonials on the radio programs. Youth NGO staff were trained to mobilize youth and carry out campaign activities.

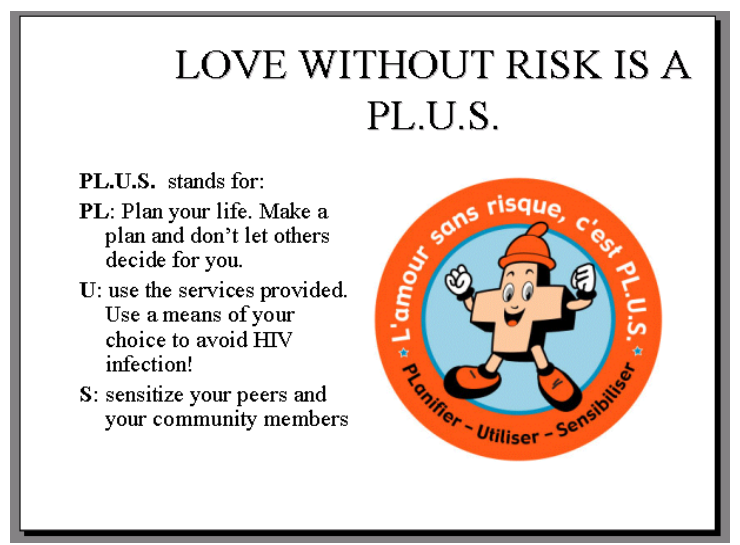

The study compared sexual attitudes and behaviors from a 2001 baseline survey of about 2,700 girls and boys to a 2003 follow-up survey among about 2,200 youth. About 65 percent of those in the survey were exposed to at least one campaign activity or material. Several indicators changed in the desired direction. The percent of females who perceived peer support for sexual abstinence increased from 47 percent to 56 percent. The percent of females who discussed sexual abstinence with either parent increased from 14 percent to 23 percent. And, the percent of males who encouraged someone to use condoms increased from 76 percent to 87 percent. Several variables went in an unexpected direction, without a clear understanding of why. The percent of single females who perceived the self-efficacy to refuse sex with someone who gives gifts declined from 74 percent to 68 percent.

Based on the research findings, the investigators recommended:

- Target audiences early, before the onset of puberty, with abstinence messages and life skills development

- Encourage adolescents to stay in school as long as possible, set high professional goals for themselves, and work towards achieving them.

- Give high visibility to positive deviants to correct the perception that most adolescents are having sex. 


\section{Session IV. Results from Horizons Studies}

\section{Introduction}

Naomi Rutenberg, Horizons

The Horizons program conducts operations research to prevent HIV and mitigate its impact. Horizons is working with a variety of youth projects including those targeting inschool and out-of-school youth and including youth both sexually active and not sexually active. The study outcomes address social norms that support communication and negotiation with peers and adults, self-efficacy, non-stigmatizing attitudes and behaviors, and protective behaviors including abstinence, partner reduction, and condom use.

The HIV youth studies revolved around two central research questions. The first is, "What can programs do for youth?" One study that addresses this question is the Transition to Adulthood study, a prospective study of adolescents in KwaZulu-Natal province in South Africa that is gathering data on sexual and reproductive health behaviors, education and employment experience, family and environmental conditions, and other factors that affect the lives of adolescents.

Another study with the Ministries of Education in Mexico, South Africa, and Thailand is exploring the role of school-based programs in meeting the needs of adolescents, using quasi- and experimental assessment designs. In the area of voluntary counseling and testing (VCT ) and youth, studies in Kenya and Uganda looked at whether youth-friendly services increase the use of, and satisfaction with, VCT among youth. One study worked with orphans in Uganda to protect their rights and to prepare them and their guardians for the death of parents. In the area of care and support, a study in Zambia introduced and evaluated a program that involved youth in the care of people living with HIV/AIDS as a way to motivate adoption of safe sex practices.

The second major research question was "What are the contextual and programmatic barriers to delivering effective youth programs?" Around the issue of VCT and youth, diagnostic studies found that youth will use VCT services if they are youth-friendly, that is, if the providers provide confidential and respectful service. Other work is currently testing strategies for making VCT services youth-friendly. Studies in Rwanda and Kenya seek to identify the best way to implement ABC (Abstinence, Be faithful, and Condom use) programs for youth. Three studies are exploring whether programs can affect community norms regarding gender and violence in Brazil, India, and Tanzania. An ongoing study in Zimbabwe is investigating the impact of psychosocial support programs for AIDS orphans; a study in Cambodia is investigating ways of mobilizing communitybased alternatives to institutional support for orphans and vulnerable children.

Dr. Rutenberg then introduced the two Horizons staff members who gave details on several research initiatives.

\section{Teaching Abstinence in Schools: Findings from Horizons Studies}

Ann P. McCauley, Horizons, International Center for Research on Women 
Dr. McCauley introduced the studies by giving some background information on three Horizons studies of school-based HIV prevention programs. All the interventions have been scaled up and are sustainable to date - they are not pilot programs. The study interventions were designed, implemented, and taught by local educators. All three studies met the ten characteristics of an effective program identified by Douglas Kirby for programs in the United States. The operations research studies used a quasi-experimental design with intervention and control groups. Surveys were completed before and several months after the intervention, and then again several months later. The studies looked at variables such as sexual activity, condom use, abstinence, number of partners, gender attitudes and respondents' feelings of being connected to family and

\begin{tabular}{|c|c|c|c|}
\hline & Mexico & South Africa & Thailand \\
\hline Number of schools & 4 & 22 & 6 \\
\hline Number of students & 2.064 & 1,140 & 1,617 \\
\hline Matched responses & \begin{tabular}{|l|}
946 thru 4 \\
rounds
\end{tabular} & $\begin{array}{l}646 \text { thru } 3 \\
\text { rounds }\end{array}$ & \begin{tabular}{|l|}
1,796 thru 3 \\
rounds
\end{tabular} \\
\hline Mean age & $16 \mathrm{yrs} 9 \mathrm{mos}$ & $15 \mathrm{yrs} 8 \mathrm{mos}$ & $20 \mathrm{yrs}$ \\
\hline$\%$ ever had sex & $\begin{array}{l}M=25 \\
F=7\end{array}$ & $\begin{array}{l}M=65 \\
F=37\end{array}$ & $\begin{array}{l}M=58 \\
F=26\end{array}$ \\
\hline
\end{tabular}
school.

The South Africa study focused on presenting abstinence as a choice that is a human right, meaning that youth did not have to have sex if they didn't want to. The intervention helped youth think about whether they were ready to have sex, whether they wanted to have sex, and whether their partner was ready. The curriculum also focused on helping youth develop refusal, negotiation, and planning skills that would help them avoid unwanted sexual contact.

A majority of youth in the South Africa study had been abstinent for the last few months, and most reported that they were abstaining from sex until they were ready. The proportion that said that they were abstaining to protect themselves from pregnancy was lower than those abstaining to prevent HIV, but still fairly high. A high proportion of adolescents approved of abstinence. Findings on adolescents' intentions to have sex in the following three months suggested that most study participants did not plan to engage in sex, and those who did, planned to have safe sex.

The Thailand study population involved youth who, on the average, were 20 years of age and enrolled in college. The intervention presented abstinence as a health protection strategy that youth could adopt. Students evaluated several strategies for avoiding unsafe sex such as not having a boyfriend or girlfriend or using condoms. Health decisions were tied to decisions in the students' personal lives. 
Dr. McCauley concluded that young people know abstinence works. Most youth are currently not active and do not intend to be sexually active. Age and sex are the best predictors of whether or not young people will be abstinent. Most young people felt that they had the right to say no to sex. In South Africa youth agreed with the message that abstinence is a good choice to protect one's health. Youth in South Africa felt that it was okay for teenagers to be abstinent. In Thailand students without partners and those living in school dormitories were more likely to abstain from sex than those with partners or those who lived with families or on their own.

\section{Teaching abstinence: South Africa}

NQI * Rights based approach

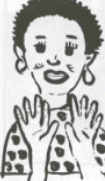

- Information

- Skills in refusal, negotiation, planning

\section{Approval of abstinence: South Africa}

Students Who Think it's a Good Idea Not to Have Sex While a Teenager

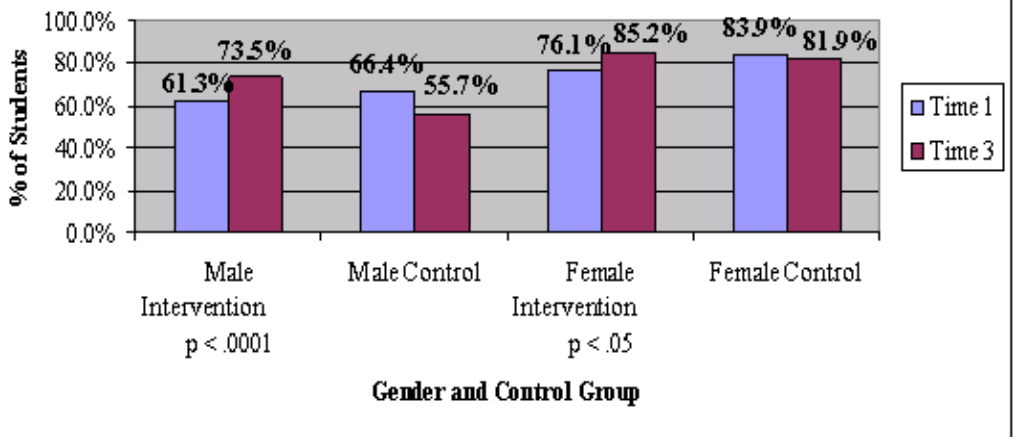




\title{
Transitions to Adulthood in South Africa
}

\author{
Lisanne Brown, Horizons
}

The study sought to investigate the impact of exposure to life skills, to document patterns and trends in the key events during adolescence, and to advance knowledge about the key external factors (such as poverty and community violence) affecting the incidence and timing of these events. South Africa was chosen as the study site for several reasons, including the high HIV prevalence rate among adolescents aged 15 to 24 years and the extreme income and gender disparities that exist within this group. This study fills a gap in research on the impact of life skills programs and on the effect of poverty on sexual and reproductive health behaviors.

The study took place in the KwaZulu-Natal region with 2,222 youth ages 15 to 24 years. All youth were interviewed in their households in 1999 and 2001. About 60 percent were between 14 and 19 years old; slightly more were females (males were harder to locate); 77 percent were African, 20 percent Asian, and the rest white and colored. From 1999 to 2001, some students left school, increased their sexual activity, or became pregnant.

The study looked at several variables, but the presentation focused on the effect of exposure to life skills education on behavior. Secondary abstinence (defined in this study as sexually initiated youths reporting no sexual partner during the 12 months preceding the survey) showed signs of significant improvement over the two-year period of the study, but this change was not attributable to life skills education. Adolescents were 3.9 times more likely to practice abstinence in 2001 compared to 1999. In contrast, consistent condom use was strongly associated with exposure to life skills education. Boys and girls exposed to life skills were 2.2 more likely to use condoms in 2001. Increased condom use was also significantly influenced by outside factors such as the maturation of youth, exposure to other programs such as LoveLife, and other changes in South African society.

In summary, the results of this analysis suggest that life skills education had more influence on condom use than on the abstinence and be faithful messages. In the future, the program should equally emphasize all prevention strategies $(\mathrm{ABC})$, including secondary abstinence. There was also evidence that exposure to the program varied by race.

The study also showed a relationship between poverty and risky behavior. Poverty predicts lower school enrollment; greater risk of early sex debut; higher risk of coercive sex, trading sex, and early pregnancy; and poorer access to media messages for females. Poor females are more likely to become pregnant before age 20. Among youth ages 14 to 18 , poor females have lower exposure to media messages (such as those on radio stations and billboards) on family planning. These finding are important to consider for program implementation. Information, education and communication (IEC) is necessary but insufficient in the context of poverty and vast inequality. Programs need to address the social, economic, and gender context within which behaviors take place. 


\section{Session V. Closing Session}

\section{Discussion on Tanzania, Côte d'Ivoire and Horizons Studies}

Several audience members and panelists commented on the targeted audience and context of interventions.

- Social and economic context play such an important role in behaviors of young people that involving the larger community seems critical. A social control approach might be more productive than a school-based approach alone, using community groups, families, and parents as key intervention targets, at least to complement a school-based project. For example, involving places where girls come together for social support might help decrease social isolation and increase economic progress, said one audience member.

- Others addressed the population targeted, including the need to include older men who have sex with younger women. How can a school-based intervention have significant impact when older men may be a key audience for transmitting the virus to school girls, especially through transactional sex, one person asked? Are we seeking behavior change among the right people? Interventions that address social norms for the broader community, together with messages targeted to youth, may have a broader impact, one person said.

- One person pointed out that the need to pay school fees in secondary schools can contribute to girls having sex for money, so school fees need to be addressed.

- Another pointed out the importance of mass media campaigns helping to highlight the dangers of having sex for money, for all involved, both young people and adults.

The role of abstinence in curricula and secondary abstinence came up in several comments.

- The term "abstinence plus" was confusing to some; it refers to including messages about being faithful and using condoms, that is, the full "ABC" message.

- Curricula can target different age groups with abstinence messages (very young) or "abstinence plus" messages. The South Africa study indicated significant interest in secondary abstinence, which shows the importance of including this message for those who are already sexually active.

The Tanzania researchers elaborated on issues raised in a question about the biological markers and self-reports. They have not yet compared the two types of measurements for the post-intervention data but intend to do so. But the association between biological and self-reports at baseline were "appalling," said Ross. About two-thirds of those who were either pregnant or HIV positive said they had never had sex. Sexual behavior seemed to be highly under-reported. 


\title{
Panel: Reflections on Key Lessons Learned
}

The day concluded with a panel of experts who offered reflections on the presentations, studies, and discussions:

\author{
Dr. Jane Bertrand, Johns Hopkins University \\ Dr. Iqbal Shah, World Health Organization \\ Dr. Doug Kirby, ETR Associates \\ Dr. Sarah Harbison, USAID
}

Dr. Bertrand of Johns Hopkins University gave what she called an historical perspective. While some of the study results were not what we might have wanted and may seem discouraging, these were good studies and their findings may in fact be quite revealing and important. In assessing the evidence regarding interventions for youth, we should remember the experience from a related field: family planning. In the late 1960s, large families were still the norm and socio-cultural barriers seemed insurmountable. Yet in the three decades since then, the total fertility rates of countries around the world have steadily declined. Interventions for youth are still relatively new, and we the practitioners in this field need to continue the search for more effective approaches.

What these studies underscore is a much greater appreciation for context. We can take some of the lessons from the family planning experience and apply them to youth. For example, we know that there are multiple factors that drive change. A tremendous amount of resources went into family planning, testing many different strategies, and we did not give up. Applied research and evaluation played an important role in developing successful programs.

Two promising themes stood out during the day, said Bertrand. First, the process evaluations and monitoring of the studies were excellent, emphasizing the importance of knowing how an intervention was carried out. Second, getting a handle on exposure seems particularly important. She offered a promising approach called "propensity score," which statistically creates a group of those not exposed matched on particular variables. While promising, the tool does not measure motivation, which is hard to measure. The take-home message, she said, was that change does not take place overnight but is cumulative and does gradually contribute to changing social norms. Reporting what did and did not work helps advance the field.

Dr. Shah of the World Health Organization appreciated the fact that so many new studies have now become available, thanks to the collective efforts by donors and researchers. These studies offer multiple insights and lessons and that is the major contribution of the work presented. However, the studies presented are complex, difficult to undertake, and difficult to interpret, especially in terms of attribution of effects of interventions. Some findings were clear: knowledge and attitudes are easier to change than behavior; process indicators seem to be easier to document than impact indicators; and costs for scaling up may be lower than a simple multiplier of the project costs, which is good news. Regarding the multi-country study with a standardized protocol and common instruments, he observed several challenges: 
- The demographic profile of youth is different in different countries. For example, HIV/AIDS is ravaging among youth in Kenya but prevalence is low in Bangladesh and Senegal. Most women are married by age 20 in Bangladesh compared to rather few in Mexico.

- The policy context is different in different countries.

- The relative importance of different interventions varies by country, for example, with youth-friendly pharmacies being more important in Mexico than in other countries in the same study.

He noted that the main challenge is to draw lessons for policies and programs, and in this respect the findings are rather confusing and disappointing. It is disheartening that the Mwanza study with a good study design and a host of interventions as well as the multicountry study did not point to a selected set of interventions that are likely to impact on adolescent reproductive health and behavior change. It is important to be able to say more than "the intervention did no harm," which was one statement reported during the day. Policy-makers are interested in a selected number of interventions with optimal impact, but there was little evidence or guidance provided on this by the studies presented. It might have been better to work with fewer interventions, maybe three or four things, that are essential to have the optimal impact and that are amenable to programmatic changes.

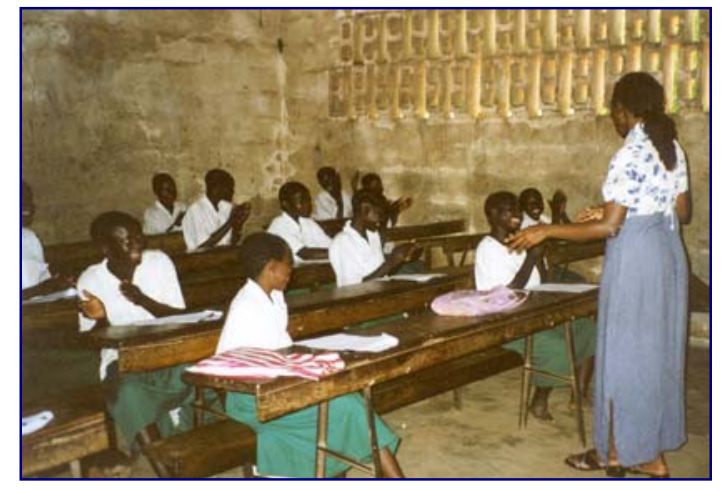

Dr. Shah had several observations regarding further framing the findings on these studies and on the development of similar future studies. He emphasized that the quality of reporting must be examined rigorously, for it is easier to report favorable changes in knowledge and attitude than a behavior change. Future studies might make better use of qualitative information and have a better selection of sites with appropriate justification. It is important to build into future studies the effect that antiretroviral therapies may have on behavior. Finally, he reiterated that information and education is a human right and this should be the basis for promoting such interventions rather the criteria of costeffectiveness or needing an evidenced-base rationale.

Dr. Kirby of ETR Associates commented first that the studies produced a vast array of useful findings on risk and protective factors; on knowledge, attitudes, and behaviors; on cost; on staff and peer turnover; and other issues. The studies showed that collecting data on behaviors of youth can be done, as well as randomly assigning youth (or schools or geographical areas), tracking them for months or years over time, and measuring multiple effects of interventions. These studies collectively show how far we have raised the bar regarding quality of studies and their impact. Years ago, some studies simply measured impact on knowledge. Now the Tanzania study, for example, measured impact after a three-year intervention and found positive behavioral effects. However, it did not significantly reduce several STIs including HIV, and some people are disappointed. Over the years, real progress has been made, more rigorous studies have been conducted, more behavioral effects have been found, and we do know much more. 
Although methods have improved, there remain methodological limitations, with findings from cross-sectional surveys being less clear than those from studies employing an experimental design. In some of the results, the low-exposure intervention group had lower scores than the comparison group while the high-exposure intervention group had higher scores. This suggests a self-selection effect. Consequently, we need more experimental designs, even though it costs more to track people over time.

The Tanzania study, with an experimental design, did change multiple behaviors among males but only one behavior among females. The conclusion should not be that changing behavior cannot lead to changes in STI rates, but rather that programs may need to change particular behaviors among particularly important groups. For example, young women may need to reduce their number of sexual partners, especially with older men who are more likely to be HIV infected, in order to reduce their HIV rates.

Dr. Harbison of USAID discussed the reports as a package of results relating to schools, communities, and health services. She saw schools as effective conveyors of information, but was not sure that they could be expected to change values or behaviors in the short run. Communities provide the greatest opportunity for clarifying values and influencing behavior changes in youth. Even though the studies showed relatively low demand for youth-focused health services, services do seem to be an essential component of a comprehensive health program. The key is to structure the school-based and communitybased components in a way that will generate demand for the health services. It is also important to consider innovative ways in which those health services can be made available to youth, especially in nonclinical settings.

Overall, it is clear that it takes considerable time to put multicomponent programs in place, to solidify them within institutions, and then to see an impact on individual behaviors. Monitoring the progress of implementation of various program components, and measuring participation of the target population is essential to understanding why programs achieve their goals or not. It is also essential for guidance in scaling up successful programs.

Dr. Harbison made several suggestions and observations about future studies. They need to be fine-tuned and to be precise about what the objectives are. Studies need to be clear about whether they are trying to change values of youth, to work with parents, to work through other gatekeepers, or to build a network. Youth need services, and programs need to consider a range of potential youth-friendly outlets, such as using pharmacies and VCT clinics as promising intervention sites. Finally, in thinking about how results of research are utilized, we need to distinguish between scaling up and diffusion. Diffusion may occur simply by individuals or organizations becoming aware of activities that have been implemented by another organization, and then just starting activities of their own. Scaling up, on the other hand, requires much more explicit thought and planning about costs, an assessment of the successful elements of the intervention, and identification of the institutions that would be involved in the scaled-up activities. 


\title{
Appendix 1. Meeting Agenda
}

\author{
8:45 - 8:50 a.m. Welcome and Introduction \\ Shanti Conly, USAID \\ Nancy Williamson, YouthNet, Family Health International \\ SESSION I Moderator: Sarah Harbison, USAID \\ 8:50 - 9:15 a.m. Setting the Stage: Learning from RH/HIV Youth Programs \\ Doug Kirby, ETR \\ 9:15 - 9:30 a.m. Introduction: Results from Frontiers Global Agenda Youth Studies \\ Susan Adamchak, Frontiers \\ 9:30 - 9:45 a.m. Senegal \\ Nafissatou Diop, FRONTIERS/Senegal \\ 9:45- 10:00 a.m. Kenya \\ Carolyne Njue, FRONTIERS/Kenya \\ 10:00. - 10:15 a.m. Coffee Break \\ 10:15 - 10:30 a.m. Mexico \\ Ricardo Vernon, FRONTIERS/Mexico \\ 10:30 - 10:45 a.m. Bangladesh \\ Ismat Bhuiya, FRONTIERS/Bangladesh \\ 10:45 - 11:00 a.m. Costs of Scaling Up \\ Barbara Janowitz, FRONTIERS/FHI \\ Session II. Moderator: Susan Adamchak \\ 11:00 - 12:00 p.m. Discussion of Implementation, Results, and Costs \\ 12:00. - 1:00 p.m. $\quad$ Lunch and materials display \\ Session III. Moderator: Nancy Williamson \\ 1:00 - 1:45 p.m. Results from a Community Randomized Trial in Rural Tanzania: \\ the MEMA kwa Vijana Project \\ David Ross, AMREF/LSHTM/NIMR \\ Bernadette Cleophas-Mazige, AMREF \\ 1:45 - 2:15 p.m. Evaluation of a Positive Deviance Youth Media Intervention in Cote \\ d'Ivoire \\ Stella Babalola, JHU/CCP \\ 2:15-2:30 p.m. Coffee break
}


Session IV.

$2: 30-2: 35$ p.m.

$2: 35-2: 55$ p.m.

2:55-3:15 p.m.

Session V.

$3: 15-4: 00$ p.m.

4:00 - 5:00 pm.
Moderator: Naomi Rutenberg

Results from Horizons Studies

Considering Abstinence in Three Studies: Mexico, Thailand, and South Africa

Ann McCauley, Horizons

Transitions to Adulthood in South Africa

Lisanne Brown, Horizons

Moderator: Shanti Conly

Discussion on Tanzania, Cote d'Ivoire, and Horizons Studies

Panel: Reflections on Key Lessons Learned

Iqbal Shah, WHO

Jane Bertrand, Johns Hopkins University

Doug Kirby, ETR Associates

Sarah Harbison, USAID 


\section{Appendix 2. Discussion of Lessons Learned from Operations Research: Youth Reproductive Health and HIV Prevention}

On September 10, 2003, the day after the meeting summarized in this report, about 40 people gathered for an informal day of discussions about the research that had been presented. The meeting was designed to provide the principal investigators of the research presented at the September 9 meeting with the opportunity to discuss their studies in more depth through informal panel discussions. Participants also included those interested in these areas of study and staff from USAID, which funded most of these studies. The purpose of the day was to discover the lessons learned from the multicomponent youth interventions studied and the research in order to guide future efforts.

The panel members, with the country of their research focus, were:

Stella Babalola, Côte d'Ivoire

Ismat Bhuiya, Bangladesh

Nafissatou Diop, Senegal

Ann McCauley, Mexico/Thailand/South Africa

Carolyne Njue and Rikka Transgrud, Kenya

David Ross and Bernadette Cleophas-Mazige, Tanzania

Lisanne Brown, South Africa

Ricardo Vernon, Mexico

The day was divided into four main sections, each of which had a set of questions posed in the agenda to provide guidance to the discussion. In reading this summary, keep in mind that summaries of the studies had been presented at the September 9 meeting, so basic information about how the study was conducted was not repeated during these discussions. Nor is it repeated in this summary.

\section{Session 1. What Have We Learned about the Design and Implementation of Youth Interventions?}

Participants began by asking for clarification about the structure of the day. Shanti Conly of USAID, the moderator for the opening session, emphasized that we would hear first from each panel member and then from the other participants. First she asked each country representative to address what they felt were the most pressing youth-related problems in their country and how the study tried to address those problems. Participants then asked questions or made comments. Next, Conly asked the country representatives to discuss what were the most important lessons learned in the program design and intervention. Again, participants then made a few comments. Below, the discussions are summarized by country (in alphabetical order).

Bangladesh. There are many youth interventions going on in the country, which still has a low HIV prevalence rate. Injecting drug use is becoming a problem. It is easier to reach females than males. Reaching employed youth is difficult. Employers do not allow them 
to spend time on education issues. Of young women ages 15 to 19 , about 50 percent are married, and nearly 70 percent become mothers before age 20. Among younger youth, 67 percent are in school, and enrollment is getting higher. Girls have a low level of knowledge about their bodies, boys, and pregnancy. Our perception of the main problem is a lack of knowledge of young girls and boys and ways to improve that; this perception drove our research design to an educational intervention. In addition, there is a lack of discourse in the community about reproductive health issues.

Sensitization of all gatekeepers is critical, including at the household, school, and community levels. Disseminating baseline findings widely helped bring some of the gatekeepers on board. Some schools were not motivated to introduce the reproductive health curriculum. Teachers had a five-day training course, and they may be getting more training. It was a brave step for teachers to introduce a reproductive health curriculum and a more participatory approach to teaching. The project also worked at the household level with parents and with school committees. Getting youth into clinics is hard. We found that many girls go for tetanus shots in anticipation of eventual pregnancy. This was not an explicit goal of the intervention, but at least they are exposed to reproductive health services and get experience with attending a clinic.

Kenya. The high HIV prevalence rates in Western Kenya, especially among girls, affect the whole community. There are an increasing number of adolescents heading households, increased incest, and more disintegration of family structures and norms. HIV permeates everything, which provides an opportunity for parents, teachers, religious leaders, and others to focus on youth and HIV prevention. The big picture issues are: Do existing programs target those in need with the right services? Reproductive health programs may not necessarily reach youth with the activities and services they need, such as livelihood programs.

The project involved many stakeholders, including three government ministries and committees at the local level that include parents, peers, and religious leaders. The project also put considerable effort into creating community ownership. While teachers and religious leaders were heavily involved, we were not very sure what messages they were giving to youth, including which topics from the curriculum were being taught and discussed.

Mexico. This is a conservative environment that views adolescents as a problem. The age of marriage is increasing; thus the length of time and opportunities for premarital sex are also increasing. The challenge was to reach youth and provide them with information and services. The project did not have a clear strategy to target married youth separately. However, it needed to pay more attention to the needs of particular groups, such as those out of school and out of work, as well as those in school. We found that gender segmentation was needed. The project was successful in conveying the message to young men to use condoms, which was well-accepted. 
Senegal. In the rural areas of the study, early marriage is a protective factor against STIs, including HIV. Most women will get married before age 20, but a growing number are not married until their $20 \mathrm{~s}$. We wanted to promote safe childbirth, because maternal mortality is high and family planning is low. The population has not yet adopted healthseeking behaviors, and many are sexually active before age 20. Women need negotiation skills and pregnancy management. We found we needed to rethink and give more attention to the social context such as community and family. Local culture revolves around social support, not autonomous decision making. The lack of reproductive health knowledge can be harmful.

The project sought to make the social environment friendlier to youth. Project planners thought meetings and seminars with stakeholders would be enough, but the messages did not diffuse down to get buy-in at the local level, at the neighborhood and parent level. We needed another level of stakeholders; if we don't have the parents, we will have problems. It is important to go to a lower level of stakeholders. The research was not designed to measure that level of buy-in and involvement. Thus, we did not have good measures of community involvement. Also, the small amount of training for teachers was not sufficient. It is also important to reinforce protective factors.

Tanzania. About 50 to 60 percent of youth finish primary school but lack livelihoods or access to more education. The country has a high incidence of STIs/HIV that starts to take off at age 16 or 17, with 5 percent of girls infected by age 17. Boys tend to be infected at an older age. So we need to work especially with females ages 15 to 19 and males ages 20 to 24 . While average sexual debut is around 15, probably earlier, there is very little discussion between elders and youth about sex except admonitions to abstain. There is a lot of denial about HIV, and no effective school-based sexual health education. There are lots of misconceptions, and gender- and age-based power relationships are very important. We decided to keep peer educators as a strategy for out-of-school youth because only a small proportion of young people go on to secondary schools. Anecdotal evidence beyond the study results indicate that youth are not being well received in health services, lack real access to condoms, have misconceptions about condoms, and want income generation activities.

With the in-school program, we thought it would be a peer-led program, but the curriculum had to be done during school hours, and the teachers needed to be included and accept the curriculum. Peer educators were involved, which probably changed the discourse some, but teachers have to be heavily involved to attain credibility. The community involvement intervention was minimal and inexpensive, focusing on a oneweek health fair and competition.

Ideally, an adolescent project would be linked to larger comprehensive community interventions involving social norms, mass media, intergenerational sex, etc., not just adolescents, and with more explicit involvement of religious leaders. Condom distribution was an obstacle, with availability only at health facilities. With PSI's help, a new distribution system was set up, with youth peer educators selling condoms at a low price. Even so, condom distribution was limited and problematic. Health services were 
the easiest to work with, and research showed they became more youth-friendly. However, this in-service training was the biggest cost; if integrated into pre-service training, the cost would be much smaller. We need a mix of ideas and ownership from the government and NGOs.

\section{Session 2. Design and Implementation of Interventions (continued)}

Nancy Williamson of YouthNet, the moderator of this session, asked the country representatives and participants to address several specific topics.

1. Did we learn anything about ABC messages? (This discussion was not structured by country.)

- The studies emphasized different parts of $\mathrm{ABC}$, depending on the context.

- In Senegal, at the field level, teachers and others taught only A and B and had successes from the community's viewpoint, but did not have much discussion about or use of condoms.

- These are strategies to use at different times, and the context is crucial. Large numbers of boys and girls are sexually active (with multiple partners) by age 15 or 16 in some of the countries studied. But some of them may choose secondary abstinence, if given education and support for that choice.

- It is important to clarify what we mean by abstinence: delay in sexual debut or secondary abstinence or both.

- In Kenya, the teachers chose to deliver only the abstinence message, and it appears to have made a difference, as sexual debut age was higher at the end of the intervention.

- The Tanzania project decided that it should not promote only abstinence, but should give as many messages and skills as possible.

- Whether A, B, or C messages work best depends on where you do the study.

- More attention needs to be given to "B."

- The messages need to have a context; investments are made in adolescents who will become adults, so that discussing the benefits of delaying sex is one means of investing in youth. In addition to affecting youth behaviors, the messages may influence youth's understanding of adulthood as well as adult behaviors.

- Messages about partner reduction need to be clear, including the dangers of serial monogamy as well as multiple concurrent partners. Programs need to be careful not to suggest that having just one partner at a time is all right.

- Other aspects of abstinence that need to be addressed include the impact of involuntary first sex and coercive sex, as well as age mixing and partner selection. The number of partners is important as well as who those partners are. Partners' characteristics are very important, including their HIV status. But without the availability of VCT sites, youth will not know who is HIV positive.

2. Is there any evidence that youth involvement made programs better or more effective? Bangladesh. Teachers sat down with students to get their feedback on the curriculum. More involvement was needed in the community, outside of the classroom. Youth said 
they wanted to do drama and events to reach more out-of-school youth. In the future, youth should be involved from the beginning, including with curriculum development and evaluation.

Kenya. Youth were involved in all aspects of the project, and that took a lot of time, including getting them to grasp all of the information. We are not sure we could track any impact or results from this involvement other than the impact on the involved youth themselves. About 25 percent of the youth in the project received contact from a youth peer educator. Youth liked involvement in clubs in school. Youth involvement was not as useful for out-of-school youth (teenage mothers, etc.).

Mexico. The project tried to involve both in-school and out-of-school youth. We are not sure how well the youth involvement worked. At the community level, the cost ratio may not justify the amount of effort and the activities that involved youth, such as a poetry contest. Also, these activities do not seem to reach the higher risk youth who need the information and support.

Senegal. There is a value in having youth involved, but it can be challenging in planning. It is important to pick the right networks of youth. More time is needed to take into account the differing views and experiences of varying groups of youth. The education level of youth can be an important factor. Some youth wanted to have a parade, and we didn't want to disappoint them as it was their initiative, even though it was not likely to have much impact on the project outcomes. It is harder to keep their interest in more difficult tasks such as going through the curriculum.

Tanzania. Peer educators were facilitators for activities in reaching other youth in villages. Youth helped others buy into the project. They helped design intervention materials. It is important to involve youth and give them a sense of ownership. In the future, we would try to involve the recipients of the services more. What are the youth saying during the project? We need to get feedback from them, just like adults.

The comments and discussion that followed included these points:

- Interventions based on theory have best results. Did theory enter into design? Did some theories work?

- It is helpful to specify boundaries of what works and does not - such as in-school vs. out-of-school, boys vs. young men. How does youth involvement vary? For example, young men who were out-of-school preferred to have a mentor.

- There could be value in focusing on a particular question about youth involvement with a specific study. In such large studies as these, it is hard to tease out impact of youth involvement.

- Youth involvement has multiple levels and can be time-intensive and costly to implement. Using peer educators can be a strategy for broader program goals, as well as youth involvement. Including youth on an advisory board that is designing the intervention is also useful.

3. What are some of the ethical issues in research and interventions with youth?

Bangladesh. Interviewers asked mothers for permission to interview youth. 
Kenya. Researchers are currently working with the ministries to replicate what worked well into the control area. They are looking closely at the data regarding what interventions afforded the greatest impact so as to emphasize those interventions in the replication process. Another ethical issue that arises is how much to promise to a control area at the beginning of a project, before research results are known. If an intervention is not clearly effective, is there an obligation to introduce it in the control area?

Senegal. Project staff obtained permission from parents, as well as from the chief in the village and other neighborhood leaders - a lengthy and delicate process. Because of high illiteracy, verbal consent was obtained instead of written consent.

South Africa. The project had to get parental permission by law for 14- and 15-year-olds but not for those 16 and over. In doing the household survey, that was not a big problem. The Society for Adolescent Medicine includes guidelines for doing such research with adolescents, including working with institutional review boards (http://www.adolescenthealth.org/html/Adolescent_Health_Research_Guidelines.pdf).

Tanzania. Meetings with a school committee facilitated a system for getting written permission from parents and allowing for an opt-out approach. Information on each of the survey rounds was given to parents. If they were uncomfortable with any questions, they could report back to the school. A few parents had their children opt out. There was also "passive" opt out, where some simply didn't participate. Regarding biological markers in Tanzania, traditional protections were included such as treatment for STIs that emerged during screening. Elaborate procedures were followed to keep results of tests confidential and anonymous, including keeping results away from parents. The project identified a future issue of dealing with child-headed households and the need for a protective/legal services person who can protect them from feeling coerced into accepting the tests and other procedures.

\section{Session 3. What Have We Learned about Doing Youth Intervention Research?}

Sarah Harbison of USAID, who moderated this session, framed this session with this construct on how to think about operations research and the interventions used:

Problem $\rightarrow$ Objective

$\rightarrow$ Identification of intervention

$\rightarrow$ Implementation of intervention

$\rightarrow$ Is the intervention in place and how do you measure that? That is, have providers, teachers, and youth changed their behaviors toward youth? And, do teachers teach, and do peers promote, what they are supposed to emphasize?

$\rightarrow$ Does the intervention stay in place (monitoring and evaluation)?

$\rightarrow$ What is the impact on the objective?

$\rightarrow$ What is the impact on the problem? 
Comments on this way of looking at operational research (OR) studies included:

- An intervention project needs an MIS system to monitor what happened, including the costs: who and how many attended training, what occurred during the intervention, etc. Several commented on how critical this is for accurate measurement of the intervention.

- The Kenya project tried to use existing resources but had time constraints and could not do everything that was planned. It is useful in the design stage to see if there is an additive effect with schools.

- In Mexico, a lot of work was done with volunteers, who in turn trained others. Hence, it often did not have a complete MIS record of activities because it was hard to keep in touch with all the volunteers and there was no strict definition of a "multiplier." Also, there was a lot of turnover, which complicated the reporting.

- Monitoring what kind of exposure is occurring in the control group is also important. If control groups receive the same information or services from another source, this will affect outcomes. Need to measure this exposure and monitor it.

- Capturing measures of quality is important. What did teachers teach? Did they do an activity but not in the way we wanted it to be done? For example, was a clear message communicated, one of the elements of successful sex education programs. Quality measures need to be clearly defined.

- The Senegal project maintained the MIS, and it was a lot of work. Supervisor work is useful but difficult to monitor and record in the MIS. Also, training of trainers is important. Everything planned in the intervention was done. Threats to validity of findings, recorded in project report, include exposure to other programs simultaneously taking place and other external factors.

- Regarding monitoring school programs, you can match observations of teachers with reports from students on a survey. Horizons found a strong association in South Africa but none in Thailand.

- In Tanzania, small things helped the monitoring process such as pupil exercise books, which were reviewed. A one-day visit to schools before doing intervention helped set up the monitoring process.

A number of people commented on the issue of determining the type of intervention. The key thing is to figure out what the intervention should be in order to address the most important problem. If you have a perfectly monitored evaluation but the wrong intervention, it doesn't solve the public health problem. But how does a research team determine the best intervention? Discussions need to occur on the big, macro picture such as implementing the $\mathrm{ABC}$ approach as well as the micro level of the minutiae of implementing a study. This discussion involved whether a clinical infrastructure is needed as much as say, faith-based institutions, and whether older men need to be targeted through addressing social norms because of intergenerational and transactional sex. Research design issues then come into play, such as the random allocation of intervention and control sites.

Several priorities for new research were discussed:

- Senegal - protective factors in adolescence pregnancy and ways to improve management of pregnancy 
- Bangladesh - parent-adolescent communication

- Kenya - relationship of poverty alleviation with HIV infection

- Tanzania - poverty alleviation and other protective factors from HIV infection; and what is feasible to do with a community as a whole that could be sustained and scaled up regarding overall sexual norms

- Others - distinguish between short-term and long-term goals, including changes in education, livelihood skills, and community norms. One small intervention cannot address macro issues but that doesn't mean it isn't needed.

\section{Session 4. What Have We Learned about Scaling up Youth Interventions?}

Susan Adamchak of FRONTIERS moderated this session, posing the question of what interventions from the various studies should be scaled up and what should not.

In Kenya, the researchers are doing further analysis of the data to see if there are some elements that should move forward on an expanded level. The scaling up will be a gradual process. The project needs to allow government ministries to decide what they think should be scaled up. Meanwhile, parts of the project will take some time to fine tune. For example, the project might have been stronger if the government had collaborated with the health care providers to offer closer supervision and encouragement to reach out to adolescent clients.

In Bangladesh, the school curriculum is part of a scale-up process, being utilized as a resource by the Global Fund to Fight AIDS, Tuberculosis, and Malaria. In Tanzania, sex education in schools is important because of the high HIV rates. Youth-friendly services also need to be part of any scale up. In Senegal, the project is considering how it might be part of other work that is going on in the country.

Several participants discussed the principles to consider regarding replication, such as the role of the community and distinguishing the elements of an intervention to be scaled up. It is important to determine whether the impact was specific to a particular site or has the elements that can be scaled up. Replicating gradually provides an opportunity to evaluate the process as you go. And, cost is an important issue. You can scale up particular pieces depending on the relative costs involved.

Another theme of the discussion was identifying the "best" elements of an intervention and the methods for doing that. Showing effectiveness in behavior change has a long lag time, so establishing criteria for the "best" elements is challenging. Often, an impact evaluation on an intervention is done too early and does not incorporate what has been learned over the longer term.

So, what criteria are used in the shorter term? Affordability and some measure of effectiveness are important considerations. Ideally, you would find out what was most effective in multiple sites before replication. Regarding school programs, it is important to pick out the best elements, include teacher training, and include a monitoring of 
quality, not go to scale with just anything. A region or country may not get to the "best" immediately due to political exigencies as well. We need to evaluate as we move toward the best, continuing to improve and further scale up.

One issue is whether to focus on the many or the few - whether to give some information to everyone or a lot to a few. Mass media takes a little information to many people and is one approach to going to scale. But most media requires back up from other programs (VCT, reproductive health clinics, commodities, etc.). Unfortunately, we can't wait for a lengthy scale-up process with HIV but must scale-up before we have all the answers. One issue with mass media is having backup services available. Other approaches might link schools to clinics.

The organizers thanked the participants for their thoughtful comments and presentations and mentioned that a summary of both the September 9 and September 10 meetings would be made available on YouthNet's Web site, along with the PowerPoint presentations from the September 9 meeting. 